\title{
Behavioral Ecology and Sociobiology The relative importance of body size and UV coloration in influencing male-male competition in a Lacertid lizard --Manuscript Draft--
}

\begin{tabular}{|c|c|c|}
\hline Manuscript Number: & \multicolumn{2}{|l|}{ BEAS-D-18-00411R5 } \\
\hline Full Title: & \multicolumn{2}{|c|}{$\begin{array}{l}\text { The relative importance of body size and UV coloration in influencing male-male } \\
\text { competition in a Lacertid lizard }\end{array}$} \\
\hline Article Type: & \multicolumn{2}{|l|}{ Original Article } \\
\hline Corresponding Author: & \multicolumn{2}{|l|}{$\begin{array}{l}\text { Gabrielle Names, M.S. } \\
\text { University of California Davis } \\
\text { Davis, CA UNITED STATES }\end{array}$} \\
\hline \multirow[t]{4}{*}{ Order of Authors: } & \multicolumn{2}{|l|}{ Gabrielle Names, M.S. } \\
\hline & \multicolumn{2}{|l|}{ Mélissa Martin } \\
\hline & \multicolumn{2}{|l|}{ Arnaud Badiane } \\
\hline & \multicolumn{2}{|l|}{ Jean-François Le Galliard } \\
\hline \multicolumn{3}{|l|}{$\begin{array}{l}\text { Corresponding Author Secondary } \\
\text { Information: }\end{array}$} \\
\hline Corresponding Author's Institution: & \multicolumn{2}{|l|}{ University of California Davis } \\
\hline \multicolumn{3}{|l|}{$\begin{array}{l}\text { Corresponding Author's Secondary } \\
\text { Institution: }\end{array}$} \\
\hline First Author: & \multicolumn{2}{|l|}{ Gabrielle Names, M.S. } \\
\hline \multicolumn{3}{|l|}{ First Author Secondary Information: } \\
\hline \multicolumn{3}{|c|}{ Order of Authors Secondary Information: } \\
\hline Funding Information: & $\begin{array}{l}\text { Centre National de la Recherche } \\
\text { Scientifique } \\
\text { (Not applicable) }\end{array}$ & Not applicable \\
\hline Abstract: & \multicolumn{2}{|c|}{$\begin{array}{l}\text { Communication via color signals is common in natural systems. Ultraviolet (UV)-blue } \\
\text { patches located on the outer-ventral scales of some Lacertid lizards are thought to be } \\
\text { involved in male-male competition. However, the mechanisms that maintain their } \\
\text { honesty remain unknown. Here, we use the common wall lizard Podarcis muralis to } \\
\text { test whether the lateral UV-blue spots are conventional signals, the honesty of which is } \\
\text { guaranteed by receiver-dependent costs, and discuss their potential role as an } \\
\text { amplifier of body size. We first described the morphology and reflectance properties of } \\
\text { lateral UV-blue spots in common wall lizards and investigated how they influence male- } \\
\text { male competition. Spot size and number, UV chroma, and conspicuousness } \\
\text { (calculated using vision models) were significantly greater in adult males relative to } \\
\text { adult females and adult males relative to juveniles. Total spot area (and not spot } \\
\text { number) of adult males was positively correlated with body size. We conducted staged } \\
\text { competition encounters between focal males and smaller or larger rivals with control or } \\
\text { manipulated spots. Spots were enlarged in small rivals and reduced in large rivals to } \\
\text { disrupt the phenotypic correlation between spot area and body size. Aggressiveness } \\
\text { and dominance were positively influenced by body size in control encounters. Spot } \\
\text { manipulations resulted in greater submission and less aggressiveness in focal males. } \\
\text { These results contradict the predictions associated with conventional signals and } \\
\text { amplifiers, but suggest that spots contributed to opponent evaluation during short- } \\
\text { distance encounters between competing males. }\end{array}$} \\
\hline Response to Reviewers: & $\begin{array}{l}\text { Response to Editor-in-Chief's Com } \\
\text { COMMENTS FOR THE AUTHOR: } \\
\text { Associate Editors comments: } \\
\text { This paper has undergone several } \\
\text { expert over these successive versi }\end{array}$ & $\begin{array}{l}\text { of reviews. It has been reviewed by one } \\
\text { agrees that it has improved considerably. }\end{array}$ \\
\hline
\end{tabular}


The authors have also adequately addressed that reviewers minor comments from the most recent round of reviews. I am satisfied that the MS is now suitable for publication in BES.

My comments:

see Word file corrected with track change. Please check the corrections, and if agree, accept them and resubmit a clean version.

Our response: We thank the Editor-in-Chief for their corrections. All changes were made and a clean version of the manuscript has been submitted.

line 192 AND 850 AND 854: Indicate the meaning of "SVL"

Our response: We thank the Editor-in-Chief for catching this. SVL has been specified at all of the above locations.

line 368 AND 825: Indicate the meaning of "jnds"

Our response: We thank the Editor-in-Chief for this correction. Jnds has been specified at all of the above locations.

- Acknowledgments: you may wish to thank the reviewers

Our response: We thank the Editor-in-Chief for their suggestion. We have now thanked the reviewers in our acknowledgements.

- Methods: It is required that authors state in the Methods section whether blinded methods were used in papers submitted for publication in Behavioral Ecology and Sociobiology, for example by stating "To minimize observer bias, blinded methods were use when all behavioral data were recorded and/or analyzed." or "It was not possible to record data blind because our study involved focal animals in the field." Our response: We thank the Editor-in-Chief for catching this and have now added that methods and analyses were conducted blind (lines 331-332).

- Ethical Approval: ethical approval from ethics committee for this study is not clearly mentioned in the manuscript. Please add here or state that this was not required Our response: We thank the Editor-in-Chief for this information and have now added that ethical approval from an ethics committee was not necessary for this study (line 643).

- ESM: Please include the following information: article title, journal name, author names, affiliation and e-mail address of the corresponding author AND submit a clean version (without track changes)

Our response: We thank the Editor-in-Chief for their corrections and have added the above information to the Electronic Supplementary Materials. This clean version of the ESM has now been uploaded. 
Gabrielle Names

PhD Candidate

University of California at Davis

One Shields Ave.

Davis, CA 95616 USA
Pr. T.C.M. Bakker, Institut für Evolutionsbiologie

und Ökologie, Universität Bonn, An der

Immenburg 1, 53121 Bonn, Germany

and

Pr. J.F.A. Traniello, Department of Biology, Boston University, 5 Cummington Street, Boston, MA, 02215 USA

Dear Prs. Bakker and Traniello,

Thank you for allowing us to submit a new version of our manuscript entitled "The relative importance of body size and UV coloration in influencing male-male competition in a Lacertid lizard" for publication in Behavioral Ecology and Sociobiology. We have made all minor corrections provided by Editor-in-Chief Bakker. We would like to thank the Editor-in-Chief for their corrections, and we hope that they will be satisfied by this new revision. As requested, we have uploaded a clean version of the manuscript and the ESM, as well as a document detailing the changes made in this round of revisions.

Our work has not been presented to any scientific meeting and is not under consideration by any other journal. All authors agreed to the submission of this original work and they declare that there are no conflicts of interest.

We look forward to your response.

In the name of all authors, Best regards,

Gabrielle Names 


\section{Response to Editor-in-Chief's Comments}

COMMENTS FOR THE AUTHOR:

Associate Editors comments:

This paper has undergone several rounds of reviews. It has been reviewed by one expert over these successive versions who agrees that it has improved considerably. The authors have also adequately addressed that reviewers minor comments from the most recent round of reviews. I am satisfied that the MS is now suitable for publication in BES.

My comments:

see Word file corrected with track change. Please check the corrections, and if agree, accept them and resubmit a clean version.

Our response: We thank the Editor-in-Chief for their corrections. All changes were made and a clean version of the manuscript has been submitted.

line 192 AND 850 AND 854: Indicate the meaning of "SVL"

Our response: We thank the Editor-in-Chief for catching this. SVL has been specified at all of the above locations.

line 368 AND 825: Indicate the meaning of "jnds"

Our response: We thank the Editor-in-Chief for this correction. Jnds has been specified at all of the above locations.

- Acknowledgments: you may wish to thank the reviewers

Our response: We thank the Editor-in-Chief for their suggestion. We have now thanked the reviewers in our acknowledgements.

- Methods: It is required that authors state in the Methods section whether blinded methods were used in papers submitted for publication in Behavioral Ecology and Sociobiology, for example by stating "To minimize observer bias, blinded methods were use when all behavioral data were recorded and/or analyzed." or "It was not possible to record data blind because our study involved focal animals in the field."

Our response: We thank the Editor-in-Chief for catching this and have now added that methods and analyses were conducted blind (lines 331-332).

- Ethical Approval: ethical approval from ethics committee for this study is not clearly mentioned in the manuscript. Please add here or state that this was not required

Our response: We thank the Editor-in-Chief for this information and have now added that ethical approval from an ethics committee was not necessary for this study (line 643).

- ESM: Please include the following information: article title, journal name, author names, affiliation and e-mail address of the corresponding author AND submit a clean version (without track changes)

Our response: We thank the Editor-in-Chief for their corrections and have added the above information to the Electronic Supplementary Materials. This clean version of the ESM has now been uploaded. 
1 The relative importance of body size and UV coloration in influencing male-male

2 competition in a Lacertid lizard

3

4 Gabrielle Names ${ }^{\mathrm{a}, \mathrm{b} *}$, Mélissa Martin $^{\mathrm{a}}$, Arnaud Badiane ${ }^{\mathrm{a}}$ and Jean-François Le Galliard ${ }^{\mathrm{a}, \mathrm{b}}$

5

6 a Sorbonne Université, CNRS, IRD, INRA, Institut d'écologie et des sciences de l'environnement

7 (IEES), Paris, France.

$8{ }^{\mathrm{b}}$ Centre de recherche en écologie expérimentale et prédictive (CEREEP-Ecotron IleDeFrance),

9 Ecole normale supérieure, CNRS, PSL Research University, UMS 3194, 78 rue du château,

1077140 Saint-Pierre-lès-Nemours, France

11 * Corresponding author: grnames@ucdavis.edu

12

13 ACKNOWLEDGMENTS

14 We thank Cécile Vande Maele, Samuel Perret and Beatriz Decencière Ferrandière for their help

15 in the laboratory. We also thank the reviewers for their comments, which helped to improve the 16 quality of the manuscript.

17 
19 Communication via color signals is common in natural systems. Ultraviolet (UV)-blue patches

20 located on the outer-ventral scales of some Lacertid lizards are thought to be involved in male-

21 male competition. However, the mechanisms that maintain their honesty remain unknown. Here,

22 we use the common wall lizard Podarcis muralis to test whether the lateral UV-blue spots are

23 conventional signals, the honesty of which is guaranteed by receiver-dependent costs, and

24 discuss their potential role as an amplifier of body size. We first described the morphology and

25 reflectance properties of lateral UV-blue spots in common wall lizards and investigated how they

26 influence male-male competition. Spot size and number, UV chroma, and conspicuousness

27 (calculated using vision models) were significantly greater in adult males relative to adult

28 females and adult males relative to juveniles. Total spot area (and not spot number) of adult

29 males was positively correlated with body size. We conducted staged competition encounters

30 between focal males and smaller or larger rivals with control or manipulated spots. Spots were

31 enlarged in small rivals and reduced in large rivals to disrupt the phenotypic correlation between

32 spot area and body size. Aggressiveness and dominance were positively influenced by body size

33 in control encounters. Spot manipulations resulted in greater submission and less aggressiveness

34 in focal males. These results contradict the predictions associated with conventional signals and

35 amplifiers, but suggest that spots contributed to opponent evaluation during short-distance

36 encounters between competing males.

37

38 KEYWORDS: Intrasexual competition, Podarcis muralis, UV coloration, Territorial conflict 39 
41 Many animals use color to communicate. During intraspecific resource competition, some

42 species use color signals as an assessment tool to determine if they should engage in or avoid

43 conflicts. Studies have found that in non-mammalian vertebrates, UV coloration can be a good

44 indicator of fighting ability or aggressiveness. We tested whether and how the UV-blue spots of

45 common wall lizards play a role in male-male competition by studying the properties of their

46 spots, and then used that information to design and conduct competition experiments between

47 males involving spot manipulation. Both body size and spot manipulation influenced aggression

48 and submission during encounters. In particular, results suggest that spot manipulation disrupted

49 mutual assessment and thus that spots play a role in competition signaling in male common wall 50 lizards.

51

\section{INTRODUCTION}

53 Animals use conspicuous color patterns as signals in a variety of social interactions ranging from

54 mate choice to competition, and these signals often convey information about individual quality

55 (Bennett et al. 1994; Etman et al. 2001; Candolin 2003; Doucet and Montgomerie 2003;

56 Seehausen and Schluter 2004; Searcy and Nowicki 2005; Pryke and Griffith 2007). Resource

57 competition often involves signals that are honest indicators of the signaler's tendency or ability

58 to fight (Rohwer 1975; Maynard Smith and Harper 2003). Several mechanisms have been

59 proposed that guarantee signal honesty when interests of signalers and receivers oppose (e.g.,

60 resource competition). Signal honesty can be maintained by an incorruptible, inherent

61 relationship between signal and quality (i.e. low-cost indices) or by differential costs (or

62 benefits) associated with signal expression that are conditional on the signaler's quality (i.e.

63 strategic costs, Zahavi 1975; Dawkins and Guilford 1991; Searcy and Nowicki 2005; Bradbury 
64

65

66

67

68

69

70

71

72

73

74

75

76 77 2006).

78

79

80

81

82

83

84

85

86

and Vehrencamp 2011). These costs may be directly related to the production and maintenance of signals (i.e. handicap signals, Searcy and Nowicki 2005) or behaviorally imposed by conspecifics based on an arbitrary convention (i.e. conventional signals, Guilford and Dawkins 1995; Johnstone 1998; Candolin 2000; Vehrencamp 2000). Conventional signals, such as "badges of status" in birds, are cheap to produce but their honesty is maintained by social costs imposed by receivers that penalize signalers displaying a signaling level that does not match their fighting capacity or individual quality (Senar 1999; Searcy and Nowicki 2005; Ligon and McGraw 2016). In addition to indices and costly signals, Hasson suggests the evolution of amplifiers as yet another route to signal honesty (Hasson 1989, 1990, 1991). Amplifiers are lowcost signals that do not directly inform on the signaler's quality, but act as a "standard" against which other signals or cues are evaluated (Castellano and Cermelli 2010). By improving the detection of signals or cues by intended receivers, amplifiers impose differential efficacy-related benefits on signalers rather than differential strategic costs (Hasson 1997; Hebets 2004; Harper

In recent years, studies have shown that ultraviolet (UV) coloration in non-mammalian vertebrates is widespread (Whiting et al. 2006; Roberts et al. 2009; Siebeck et al. 2010) and that many of these species have UV-sensitive vision systems (Bennett et al. 1994; Carleton et al. 2000; Smith et al. 2002; Pérez i de Lanuza and Font 2014). Mounting evidence suggests that UV coloration can act as an honest signal of male aggressiveness or fighting ability in birds, fishes and reptiles (Keyser and Hill 2000; Siebeck 2004; Siefferman and Hill 2005; Pryke and Griffith 2006; Stapley and Whiting 2006; Whiting et al. 2006; Rick and Bakker 2008; Rémy et al. 2010; Bajer et al. 2011; Martin et al. 2015b; Martin et al. 2016). For example, in the Augrabies flat lizard Platysaurus broadleyi, UV throat color is an honest predictor of fighting ability (Whiting 
87 et al. 2006), and in the European green lizard Lacerta viridis, UV-blue nuptial coloration in

88 males signals dominance (Bajer et al. 2011). UV signals have also been shown to co-vary with

89 male phenotypic quality (e.g., Doucet and Montgomerie 2003) and their expression can be

90 constrained in stressful environments (e.g., McGraw et al. 2002; Bajer et al. 2012). Although

91 debated, it has also been suggested that UV signal expression may be subject to developmental

92 costs due to the structural coloration production mechanisms (Keyser and Hill 2000; Siitari et al.

93 2007; Vedder et al. 2010). Other types of costs, such as receiver-dependent costs (e.g., social

94 costs) associated with conventional signals, could also maintain the honesty of UV signals

95 (Searcy and Nowicki 2005), but empirical evidence is lacking.

Alternatively, a growing body of literature suggests that color signals could convey

97 information as part of a multicomponent signaling mechanism (Grether et al. 2004). During male-male competition, signaling displays often involve multiple sensory modalities and convey

99 pieces of information from various parts of the body (Rowe 1999; Hebets and Papaj 2005). For

100 example, the dewlap extension signal in male anole lizards (used to signal bite force,

101 Vanhooydonck et al. 2005) is enhanced by the dewlap's coloration (Fleishman et al. 1993;

102 Fleishman 2000), and Ord et al. (2015) suggested that the dewlap's morphology and coloration

103 evolved to amplify the detection of head bobbing behavior. In this context, UV patches could

104 function as amplifiers (Bogaardt and Johnstone ; Hasson 1989) by facilitating the detection or

105 discrimination of other signals or cues, such as body size, behavioral displays, or other attributes

106 from the same or adjacent color patches (Fitzpatrick 1998; Taylor et al. 2000; Grether et al.

107 2004). UV color patches, in particular, are often located along body parts such as necks, mouth

108 corners, and flanks, which makes them good candidates as amplifiers of other quality signals or

109 cues (e.g., Lappin et al. 2006). For example, the male collared lizard Crotaphytus collaris has 
110

111

112

113

114

115

116

117

118

119

120

121

122

123

124

125

126

127

128

129

130

131

132

white and UV reflective mouth corners that function as amplifiers during gaping displays by drawing attention to the jaw muscles, which inform on physical strength (Lappin et al. 2006). However, to our knowledge, the amplifier hypothesis has not been experimentally tested on UV coloration displays.

Due to their distinctive lateral UV-blue patches (hereafter referred to as "UV-blue spots", Pérez i de Lanuza et al. 2014), some lacertid lizards are good model systems to investigate alternative mechanisms of honest signaling, such as conventional signals or amplifiers. In several species, the UV-blue spots (located on the outer-ventral scales of the flanks) are highly sexually dimorphic and dichromatic. Although females of some species display faint spots, which appear blue to the human eye, males alone display UV-blue spots with a marked reflectance peak in the UV range, which is highly conspicuous (Pérez i de Lanuza and Font 2014, 2015; Martin et al. 2015a). Several lines of evidence suggest that UV-blue spots may serve in male-male resource competition, but the information content of these traits and the mechanisms responsible for their evolution are contested. First, although the strategic costs associated with these spots remain unknown, their presence both during and outside the breeding season suggests they respond to both natural and sexual selection (Martin et al. 2015b). Second, studies of spot conditiondependence and status signaling have produced contradictory results regarding inter-individual variation in spot number, size and UV reflectance. López et al. (2004) and Cabido et al. (2009) found that spot number correlated with body size and condition in the Iberian rock lizard Iberolacerta monticola. Pérez i de Lanuza et al. (2014), however, demonstrated that the UV chroma of the second rostral-most spot correlated with body condition in the common wall lizard Podarcis muralis. In addition, while López et al. (2004) found a relationship between spot presence (vs. absence) and aggressiveness in I. monticola, Pérez i de Lanuza et al. (2014) 
133 emphasized the importance of UV hue in signaling combat ability in P. muralis. Then, Martin et 134 al. (2015b) found that $P$. muralis spots play a role in opponents' mutual assessment of fighting 135 ability. Also along these lines, some studies have found a relationship between spot number and 136 body size (López et al. 2004; Martin et al. 2015b), thus raising the possibility that spot number 137 may be an amplifier of body size, found to correlate with male fighting ability in I. monticola 138 (López et al. 2002) and P. muralis (Edsman 1990; Sacchi et al. 2009). However, a manipulative 139 study of the blue (but not UV) coloration of I. monticola, in which some spots were masked, 140 failed to validate this hypothesis (López et al. 2004).

The above results suggest that UV-blue spots are involved in P. muralis signaling but that 142 their effects may be subtle and/or depend on multiple features of the spots themselves or other 143 qualities of the signaler (i.e. body size). P. muralis males display UV-blue spots, which run along 144 a large portion of the flanks, and body size is a predictor of $P$. muralis aggressiveness and 145 fighting ability (Edsman 1990; Sacchi et al. 2009). However, the relative roles of body size and 146 UV reflectance in male-male competition are unknown. The aims of our study were to 1) 147 investigate multiple color and morphological properties of the UV-blue spots, 2) experimentally 148 examine whether the honesty of these UV-blue spots is maintained by social costs characteristic 149 of conventional signals, and 3) explore their potential role as amplifiers of body size. We 150 designed behavioral assays consisting of dyadic encounters between non-manipulated focal 151 males and differently sized opponents (2-4 mm larger or smaller than the focal) with UV-blue 152 spots that were or were not UV-enhanced/reduced (hereafter "manipulated" or "control" 153 opponents, respectively). We manipulated the UV-blue spots to create an asymmetry between 154 UV-blue spot area and body size, so as to obtain bluffers (small males with enlarged spots) and 155 Trojans (large males with reduced spots). If spot area functions as a conventional signal, we 

Pérez i de Lanuza et al. 2014; Martin et al. 2015a).

\section{Sampling and measurements} aggression and fighting by both focals and opponents.

\section{MATERials AND MethodS}

\section{Study species}

would predict that deceptive males would pay a cost for being dishonest in the form of increased aggression from focal males (Ligon and McGraw 2016). Therefore, we expected deceptive males to produce fewer displays of aggression and greater displays of submission compared to their respective controls. If, however, spot area acts as an amplifier of body size, we predicted that conflicting body size and spot area traits would cause rival assessment to take longer or not be possible by visual assessment alone, thus resulting in an increase in physical assessment via

The common wall lizard $P$. muralis is a small (snout-vent length, SVL, 48-67 mm), oviparous, polyandrous lacertid lizard widely distributed in semi-open habitats in Europe (Speybroeck et al. 2016). Adult males are territorial during reproduction; large males are more aggressive and defend large territories, while smaller males are less aggressive and defend small territories (Edsman 1990). P. muralis is characterized by a conspicuous, discrete belly color polymorphism (Speybroeck et al. 2016; Andrade et al. 2019). In the study area, males have white, orange, or yellow bellies and females have white or yellow bellies (though yellow is rare in both sexes, J-F Le Galliard personal observation; Sacchi et al. 2009; Galeotti et al. 2010). In this study sample, we captured no individuals with yellow bellies. Lateral UV-blue spots, which appear blue to the human viewer and span a large portion of the flank (see Fig. S2), are displayed by a majority of individuals, although previous analyses showed that spots are sexually dimorphic (reduced or absent in females) and sexually dichromatic (UV-reduced in females, Vacher and Geniez 2010; 
179 Our study was conducted on a wild population of $P$. muralis located in central France (CEREEP180 Ecotron IleDeFrance, France, $60 \mathrm{~m}$ a.s.1., $\left.48^{\circ} 17^{\prime} \mathrm{N}, 2^{\circ} 41^{\prime} \mathrm{E}\right)$. All procedures complied with laws 181 on animal experimentation and animal care in France and Europe (permit Ce5/2011/044).

182 Lizards were captured by noosing during the breeding season in the second week of March of 183 2014. In total, 15 juvenile (4 male, 4 female, 7 unidentified sex) and 60 adult (37 male, 23 184 female) lizards were captured. Age class was identified by size (adults $>55 \mathrm{~mm}$ ), and sex by 185 presence of femoral pores (visible to the naked eye) and the hemipene caudal bulges in the 186 proximate tail. Immediately following capture, we used a spectrometer (Jaz Series, JAZ-ULM187 200; Ocean Optics Inc., Dunedin, FL, USA) to obtain ambient irradiance profiles of light at the 188 capture locations, for use in models of the lizard vision system. Individuals were taken to the lab 189 to measure body size (snout-vent length [SVL] and total length, $\pm 1 \mathrm{~mm})$ and body mass $( \pm 1 \mathrm{mg})$. 190 Spots were counted and their surface area measured $\left( \pm 0.001 \mathrm{~mm}^{2}\right)$ in Image J $($ Schneider et al. 191 2012) using digital scans of lizard flanks (3.8 megapixels, produced using CanoScan LiDE 192 700F). To produce scans, lizard flanks were pressed securely but gently against the scanner, 193 situated just below a grid $(1 \mathrm{x} 1 \mathrm{~mm})$ to scale. Then, two ventral scales of each individual were 194 marked using a non-invasive heat-branding method to allow for individual identification during 195 behavioral experiments (Vervust and Van Damme 2009). Spectral reflectance of all UV-blue spots of all individuals was measured using a USB1972000 spectrophotometer, a HL 2000 (Halogen-Deuterium) light source, and a 400- $\mu$ m R400-7198 UV/VIS fiber optic probe (all products of Ocean Optics Inc., Dunedin, FL, USA). Spots smaller 199 than the size of the reflectance detector $(<2 \mathrm{~mm})$ were not measured $(\mathrm{N}=519$ out of 1159$)$ to 200 avoid spectral contamination (Badiane et al. 2017). Reflectance spectra were analyzed using 201 Avicol software version 6, which linearly interpolates spectra with one value per nm (Gomez 
202 2006). For each spectrum, we quantified intensity $\left(R_{300-700}\right)$, UV chroma $\left(R_{300-400} / R_{300-700}\right)$, and

203 UV hue (wavelength of the maximal reflectance in the UV range 300-400 nm). UV hue was not

204 calculated when there was no UV reflectance peak, i.e. when the spectrum sloped up or down

205 from 300 to $400 \mathrm{~nm}(\mathrm{~N}=93$ out of 640). We also calculated a mean spot reflectance spectrum

206 for each individual. To determine extrinsic conspicuousness of spots, one to two flank scales

207 dorsal to the UV-blue spots per lizard were measured to calculate a mean flank spectrum, which

208 was used to simplify analyses. Then, to determine extrinsic conspicuousness, eight habitat

209 background objects commonly found at capture sites ( 3 rocks, 2 bricks, 1 patch of grass, 1 tree

210 branch and 1 piece of plywood) were each measured (4-6 times) and the mean reflectance

211 spectrum for each object was calculated.

\section{Color vision model}

213 P. muralis is a typical diurnal lizard species with tetrachromatic color vision based on a single-

214 cone system that includes UV, short wavelength, medium wavelength, and long wavelength

215 sensitive photoreceptors (Martin et al. 2015a). To model the ability of wall lizards to

216 discriminate colors of conspecifics, we ran the Vorobyev and Osorio (1998) color opponent

217 vision model in Avicol (Gomez 2006), parameterized with data on eye physiology and anatomy

218 obtained from Martin et al. (2015a). This model assumes a receptor noise-limited color opponent

219 discrimination mechanism and requires data on receptor spectral sensitivities, receptor

220 abundance, and noise levels in the photoreceptors (e.g., see Vorobyev and Osorio 1998; Siddiqi

221 et al. 2004 for applications). The model calculates relative quantum catch by each photoreceptor

222 type given incident light entering the eye and the spectral sensitivity of the receptor (including

223 lens, ocular media and oil droplet absorption, and visual pigment absorbance of single cones),

224 which is then used to place color objects into a tetrahedral color space and to calculate a 
225 perceptual distance $(\Delta S)$ in the chromaticity diagram (Goldsmith 1990; Stoddard and Prum

226 2008). $\Delta S$ between two color objects was calculated following the Vorobyev and Osorio (1998)

227 model and expressed in units of multiples of just noticeable differences (jnd). Values of $\Delta S$

228 below 1 indicate that colors are inconspicuous. Receptor spectral sensitivities and receptor

229 abundance were obtained from previous data on single cones (Martin et al. 2015a), and

230 photoreceptor noise was assumed independent of light. Incident light was calculated by

231 averaging ambient irradiance profiles taken during lizard captures (parameterization details in

232 Appendix S1). We used the model to calculate $\Delta S$ of pairwise comparisons between spots vs.

233 habitat objects, spots vs. the mean flank spectrum, and the mean flank spectra vs. habitat objects.

234 This approach is similar to that used in Pérez i de Lanuza and Font (2015), but we found it

235 important to conduct these analyses in our study population before proceeding to behavioral

236 assays. Males had a greater number of UV-blue spots than adult females and juveniles, which

237 accounts for the difference in UV-blue spot sample sizes of the groups.

238 Color manipulation and behavioral assays

239 Following measurements, 35 adult males were housed individually in opaque terraria

$240(25 \times 15.5 \times 15 \mathrm{~cm})$. Lizards were housed for a total of 15 days, which included a 4-day acclimation

241 period and an 11-day experimental period. Animal care was performed by authorized personnel

242 under permit DTTP-2008-449 issued to JFLG. Each terrarium contained a thick layer of soil

243 bedding, a shelter, and a water dish. Heat and light were provided by a combination of halogen

244 and UV lamps set to a 10:14-h light-dark regime, resulting in an ambient temperature ranging

245 from 15 to $23^{\circ} \mathrm{C}$ during the dark and light periods, respectively. Lizards were fed $300-400 \mathrm{mg}$ of

246 crickets every other day and water was available ad libitum. 
Behavioral assays were performed in a temperature-controlled room in neutral arenas, to

248

249

250

251

252

253

254

255

256

257

258

259

260

261

262

263

264

265

266

267

268

269

eliminate the effect of residence advantage (López and Martín 2001; Kokko et al. 2006; Martin et al. 2016) and to focus on the effects of spots and body size on male-male competition. Arenas were composed of large opaque terraria $(45 \times 29 \times 22 \mathrm{~cm})$ containing a layer of white sand and divided by opaque plastic into two equally sized small compartments $(17 \times 14.5 \mathrm{~cm})$ and one large compartment $(28 \times 29 \mathrm{~cm})$. The small compartments served as solitary holding areas, which allowed lizards to acclimate to the new conditions. Two UVB neon tube lights (Reptisun 10.0) and one Exo Terra Solar-Glo lamp were suspended above the arena to provide UV-white light (producing an irradiance profile that included substantial UV irradiance and resembled natural lighting) and heat. The latter was positioned $20 \mathrm{~cm}$ directly over a $4 \times 9 \mathrm{~cm}$ black PVC basking plate, placed on the sand in the large compartment, to which lizards competed for access.

Dyadic encounters occurred between a non-manipulated focal male and an opponent male 2 to $4 \mathrm{~mm}$ larger or smaller than the focal (opponent lizard size range $=59-71 \mathrm{~mm}$, mean size difference with focal $=3.20 \mathrm{~mm} \pm 0.89 \mathrm{SD}$ ). Opponents were either a control or had manipulated spots. For the latter, spots were enlarged in smaller opponents (i.e. bluffers) or reduced in larger opponents (i.e. Trojans) based on a regression of spot area against SVL regression $\left(0.8 \mathrm{~mm}^{2} / \mathrm{mm} \mathrm{SVL}\right.$, see below). The modified spot area was calculated by multiplying $0.8 \mathrm{~mm}^{2}$ by twice the difference in size of the focal and opponent in order to exaggerate the spot area-SVL mismatch. Half of the total modified area was applied to each flank. Spot size of opponents was altered by applying a UV-reducing cream (UV-) or UV-enhancing marker (UV+) to add or subtract area from opponent spots. The UV-cream consisted of two inorganic agents (zinc oxide and titan dioxide) mixed with two fats (petroleum jelly and liquid paraffin) at a ratio of 6:4:50:40 per $100 \mathrm{~g}$, a combination that successfully masked UV reflectance in Martin et al. 
270 (2015b). The UV+ marker was a light blue Edding 4500 T-shirt marker pen (color code 0.10),

271 previously used to enhance UV coloration in blue tits (Johnsen et al. 2005; Kurvers et al. 2010;

272 Rémy et al. 2010) and shown here to likely enhance UV coloration in P. muralis (see Fig. S3).

273 When placed firmly on a surface at a perpendicular angle, the marker tip produced a circle of

274 approximately $0.5 \mathrm{~mm}$ diameter (area $0.8 \mathrm{~mm}^{2}$ ). As area to be added was in multiples of $0.8 \mathrm{~mm}^{2}$

275 (see above), we calculated the number of spots necessary for the area manipulation and added

276 that number of spots using firm application of the marker tip. Spots were added posterior to the

277 lizard's middle spot (uneven number of spots) or to the anterior of the middle spots (even

278 number of spots). Following marker application, we added a fat layer of petroleum jelly and

279 liquid paraffin (55.6:44.4 per 100g), with no effect on UV reflectance (see Fig. 2a of Martin et al.

280 2015b), to prevent marker rub off. Control individuals were given a fat layer treatment only. The

281 UV-cream and fat layer were applied with the thin end of a forceps. At the end of each trial, UV

282 reducing cream, fat, and marker treatments were removed through the gentle application of

283 diluted ethanol.

Out of the 35 males, 22 focal males and 13 opponent males were chosen based on size to

285 ensure the 2 to $4 \mathrm{~mm}$ difference in size between focal and opponent males. Each focal male

286 participated in a total of 4 encounters, each involving a different, randomly chosen opponent of

287 the following types: (1) control and SVL 2-4 mm longer than focal; (2) control and SVL 2-4 mm

288 shorter than focal; (3) manipulated (UV-spot area) and SVL 2-4 mm longer than focal; (4)

289 manipulated (UV+ spot area) and SVL 2-4 mm shorter than focal. Each opponent male

290 participated in no more than 8 encounters. We chose novel opponents for each test to avoid

291 familiarity among males, which has been found to significantly influence male aggressiveness in 
P. muralis (Martin et al. 2016). Encounters were spaced out by at least 1.5 days to avoid fatigue,

293 and the order of the encounters (1-4 above) was randomized.

Before each experiment, individuals were removed from their home terraria, spot treatments were applied, and each male was placed in one of the two holding compartments. After a 10-min acclimation period, the experiment began with the removal of the opaque walls.

297 One of two observers was randomly chosen to observe encounters from behind a one-way mirror 298 for a period of $10 \mathrm{~min}$. Using Jwatcher (Blumstein and Daniel 2007), we recorded the number of 299 agonistic behaviors in real-time and the number and total time of non-agonistic behaviors and

300

301

total time wall scratching using played-back video recordings. Video was recorded in black and white using a Nikon D70 digital camera positioned $30 \mathrm{~cm}$ directly above the arena. Behaviors are summarized in Table 1 below (modified from Martin et al. 2016). Observers were trained to interrupt experiments if fighting escalated to the point that it could compromise the welfare of the individuals but we observed no repeated biting or other tactile aggression events, or other serious distress signs, during the 88 trials. At the end of experimentation, lizards were individually released to their respective capture sites. To minimize observer bias, all behavioral data were recorded and analyzed blind.

\section{Statistical analyses}

We used R version 3.1.2 (R Core Team 2014) for all statistical analyses and Figs. To determine differences in spot and flank conspicuousness and spot coloration (intensity, hue, and UV chroma) of adult males, adult females, and juveniles, we used linear mixed-effects models (LMEs) with a "group" variable (three levels: adult males, adult females, and juveniles) as the fixed effect and individual identity as a random effect (multiple spots or flank scales measured per lizard). To account for heteroscedasticity in our "group" variable, we used the weights 
315 argument in our models to allow variance of the residuals to differ among group levels.

316 Residuals were tested for normality and intensity was log-transformed, hue and UV chroma were

317 rank-transformed, and chromatic contrast of flank and habitat objects was square root-

318 transformed. We performed post hoc Tukey's test to conduct pairwise comparisons of groups.

319 We also calculated variance components for spot intensity, hue (for males only), and UV chroma 320 to determine intra- and inter-individual variation for males and females.

We investigated the effect of sex and age on spot morphology, including total spot area,

322 total spot number, area of largest left flank spot, and area of largest right flank spot, using linear

323 models (LMs). Prior evidence suggests that these spot features may be indicators of male

324 behavior and/or dominance (López et al. 2004; Cabido et al. 2009; Pérez i de Lanuza et al. 2014;

325 Martin et al. 2015b). Using adult male data only, we then tested for an effect of belly color

326 morph and SVL on total spot area, total number of spots, largest left flank spot area, largest right

327 flank spot area, and mean spot UV chroma to identify spot properties that could be good

328 conventional signals or amplifiers of body size. We applied the Benjamini-Hochberg correction

329 to account for the testing of multiple spot characteristics (see Table S2). Residuals were tested

330 for normality and total spot number was log-transformed while largest left and right spots were

331 transformed using the square root function.

332 Analysis of behavioral experiment data began by summing total counts and total time data

333 for each male in each experiment. This information was used to calculate aggression score,

334 submission score, and dominance score for each male in each experiment (see Table 1), as in

335 Martin et al. (2016). We began with an analysis of control social interactions to validate previous

336 findings regarding the effect of body size and color (belly morph and spots) on male competitive

337 behavior (López and Martín 2001; Martin et al. 2015b). Using LMEs, we tested the additive 
338 effect of SVL, belly color morph, opponent size difference, and total spot area (the most likely

339 amplifier of SVL based on spot and morphology analyses) on time basking, time wall scratching,

340 aggression score, submission score, and dominance score. Random effects included lizard

341 identity and assay pair number. To determine the effect of body size and spots on behavior, we

342 conducted a second set of analyses using only data from focal males, since manipulated

343 opponents were not aware of manipulations to their spots and could therefore not respond to

344 those manipulations. We tested the effect of SVL, opponent size difference (smaller or larger

345 SVL) and color manipulation (control or manipulated) as well as the two-way interaction of the

346 latter on focal male time basking, time wall scratching, aggression score, submission score, and

347 dominance score. The Benjamini-Hochberg correction was used to account for the testing of

348 multiple behaviors and scores (see Table S3). All behavioral data were analyzed with LMEs, and

349 Satterhwaite approximations of degrees of freedom were used for control analyses. In addition to

350 the fixed effects listed above, all models included experiment observer ( 2 persons), lizard

351 sequence number (lizards were used 4 to 8 times, categorical factor), and experiment time of day

352 (morning or afternoon) in order to control for variables related to experimental logistics. To

353 control for the specific experimental trial, analyses of control interactions data also included

354 experimental trial number. Prior to behavioral analyses, residuals were tested for normality, and

355 dominance score was rank transformed. For all analyses, we began with the full model including 356 all effects and chose the best model using stepwise model selection by AIC. Results are reported 357 as mean \pm SE unless otherwise stated.

\section{Data availability}

359 The datasets generated and analyzed during the current study are available from the 360 corresponding author on reasonable request. 


\section{RESULTS}

\section{Color conspicuousness}

363 Perceptual distances between flank and habitat object colors had a mean of $6.67 \pm 0.15$ jnds (just 364 noticeable differences) with $2.5 \%$ of distances inferior to 1 jnd. There was no significant difference in the chromatic contrast of habitat objects against flanks of adult males and adult females $\left(p=0.92, \beta_{\text {adult male vs. adult female }}=0.040 \pm 0.10\right)$, adult males and juveniles $\left(p=0.16, \beta_{\text {adult }}\right.$ male vs. juvenile $=-0.23 \pm 0.13)$, or juveniles and adult females $\left(p=0.12, \beta_{\text {juvenile vs. adult female }}=0.27 \pm\right.$

0.14; Table 2). Then, chromatic contrast of UV-blue spots against habitat objects had a mean of 369 $22.79 \pm 0.14$ jnds with $0.23 \%$ of distances inferior to 1 jnd, and chromatic contrast of UV-blue spots against the mean flank had a mean of $22.18 \pm 0.36$ jnds with $0.15 \%$ of distances inferior to

3711 jnd. In both cases, the chromatic contrast of adult male spots was significantly greater than that

372 of adult female spots (spot and habitat: $p<0.001, \beta_{\text {adult male vs. adult female }}=14.62 \pm 1.43$; spot and

373 flank: $\left.p<0.001, \beta_{\text {adult male vs. adult female }}=15.00 \pm 1.49\right)$ and juvenile spots (spot and habitat: $p<$

$3740.001, \beta_{\text {adult male vs. juvenile }}=7.08 \pm 1.89 ;$ spot and flank: $p<0.001, \beta_{\text {adult male vs. juvenile }}=7.15 \pm 1.96$ ),

375 and the chromatic contrast of juvenile spots was significantly greater than that of adult female

376 spots (spot and habitat: $p<0.001, \beta_{\text {juvenile vs. adult female }}=7.55 \pm 2.02$; spot and flank: $p<0.001$,

$377 \beta_{\text {juvenile vs. adult female }}=7.85 \pm 2.11$; Table 2 ). Histograms of perceptual distances can be found in 378 Fig. S1.

$379 \quad$ Age and sex differences in spot coloration

380 First, we found that blue spots of adult males had significantly higher UV chroma compared to 381 those of adult females $\left(p<0.001, \beta_{\text {adult male vs. adult female }}=268.22 \pm 29.87\right.$, see Fig. 1$)$ and juveniles $382\left(p<0.001, \beta_{\text {adult male vs. juvenile }}=153.61 \pm 38.34\right)$, and the UV chroma of juvenile spots was 383 significantly higher than that of adult female spots $\left(p=0.015, \beta_{\text {juvenile vs. adult female }}=114.61 \pm\right.$ 
41.35). Then, we found that adult female spots had significantly higher hue compared to those of adult males $\left(p<0.0001, \beta_{\text {adult female vs. adult male }}=278.79 \pm 31.43\right)$ and juveniles $\left(p=0.0001, \beta_{\text {adult }}\right.$ female vs. juvenile $=206.06 \pm 45.64)$, but adult male and juvenile spots did not differ in hue $(p=0.20$, $\left.\beta_{\text {adult male vs. juvenile }}=-72.73 \pm 42.74\right)$. We also found no significant differences in spot intensity for adult males and adult females ( $\left.p=0.98, \beta_{\text {adult male vs. adult female }}=-0.010 \pm 0.051\right)$, adult males and juveniles $\left(p=0.073, \beta_{\text {adult male vs. juvenile }}=0.14 \pm 0.063\right)$, or juveniles and adult females $(p=0.091$, $\beta_{\text {juvenile vs. adult female }}=-0.15 \pm 0.070$ ). Finally, males showed greater inter-individual variation in terms of spot intensity and UV chroma compared to females (Table S1).

\section{Size scaling of spot characteristics}

Our results revealed that total spot area, total number of spots, largest left flank spot area, and largest right flank spot area were all significantly greater in males compared to females as well as in adults compared to juveniles with the exception of total number of spots (see Table 3 ). The difference in mean total spot area was especially striking, with mean spot area more than twice as large in males compared to females (males: $2.0 \mathrm{~mm}^{2} \pm 0.15$, females: $0.73 \mathrm{~mm}^{2} \pm 0.097, \beta_{\text {males }}$ vs. females $=0.18 \pm 0.026$ ), and more than twice as large in adults as compared to juveniles (adults: $1.5 \mathrm{~mm}^{2} \pm 0.13$, juveniles: $\left.0.66 \mathrm{~mm}^{2} \pm 0.14, \beta_{\text {adults vs. juveniles }}=0.14 \pm 0.040\right)$. In addition, male total spot area, largest right spot area, and largest left spot area were positively correlated with SVL (Table 4), but not total number of spots $\left(t_{1,33}=0.48, p=0.63, \beta=0.0079 \pm 0.017\right.$, Table 4 , Fig. 2a). The relationship between total spot area and SVL was not significant for juveniles $\left(t_{1,1}\right.$

$403=0.89, p=0.39, \beta=0.0024 \pm 0.0027)$ or females $\left(t_{1,25}=0.25, p=0.80, \beta=0.00057 \pm 0.0022\right.$, 404 Fig. 2b). Mean UV chroma of male spots was higher in orange-bellied as compared to white405 bellied individuals, but was not related to SVL (Table 4).

\section{Behavior experiments}



427 Stevens 2014).

\section{Discussion}

Regarding control experiment analyses, individual SVL, but not size difference from the rival nor total spot area, was negatively correlated with indicators of submission (wall scratching time, $\left.F_{1,40.19}=8.48, p=0.006, \beta=-9.30 \mathrm{sec} / \mathrm{mm} \pm 3.20\right)$ and positively correlated with aggression (higher dominance score, $F_{1,39.23}=5.66, p=0.023, \beta=2.69 \mathrm{~mm}^{-1} \pm 1.13$, see Fig. 3). Analyses of focal male data indicated that spot manipulation (area added or removed) and opponent size (larger or smaller than the focal) did not significantly affect wall scratching time or aggression score. However, focal males facing manipulated individuals had significantly higher submission scores than focal males facing control individuals $\left(F_{1,57}=6.57, p=0.013, \beta_{\text {manipulated vs. control }}=\right.$ $5.46 \pm 2.13$ ) and also tended to have lower dominance scores (marginally significant, $F_{1,57}=$ $\left.3.86, p=0.054, \beta_{\text {manipulated vs. control }}=-8.43 \pm 4.29\right)$.

According to our vision model, the $P$. muralis visual system can distinguish the majority of UVblue spots when viewed against a mean $P$. muralis flank spectrum and objects commonly found in their natural environments, thus corroborating previous findings involving the same species (Pérez i de Lanuza and Font 2015). UV-blue spots also had a higher extrinsic compared to intrinsic conspicuousness, which seems to reinforce the idea that visual systems are more sensible to extrinsic than intrinsic conspicuousness (Aronsson and Gamberale-Stille 2009). In addition, the relative inconspicuousness of the lizards' flanks (in this study) and dorsal surfaces (in Pérez i de Lanuza and Font 2015) seems to indicate strong selection for background matching to avoid predation, as observed in other lizard species (LeBas and Marshall 2000; Marshall and

Based on the hypothesis that male-male competition shapes the evolution of UV-blue spots, sexual selection theory predicts that adult males should evolve exaggerated UV-blue spots, 
while this trait should be minimized or absent in females, as it may be detrimental and reduce their fitness via associated costs (Promislow et al. 1992; Andersson 1994; López et al. 2004; Pérez i de Lanuza et al. 2013). Additionally, juveniles should also have reduced UV-blue spots, since young, subdominant lizards should avoid competition with adults (e.g., Mugabo et al. 2013). Previous studies have revealed strong sexual dimorphism for several UV-blue spot characteristics in adult $P$. muralis but have found no clear correlation between UV coloration and adult body size. In males, a slight negative correlation between UV chroma and body condition, as well as a correlation between UV chroma and bite force (dependent on male body size), have been reported (Pérez i de Lanuza et al. 2014; Martin et al. 2015b). The number of spots also correlates positively with body size in male Iberian rock lizards I. monticola, a sister species of P. muralis (López et al. 2004). Together, these results, along with those showing an influence (albeit weak) of spots on behavior during competitive encounters (López et al. 2004; Pérez i de Lanuza et al. 2014; Martin et al. 2015b, 2016), suggest that UV-blue spots function as potential signals of individual quality, age and/or sex (Candolin 2003).

Our study revealed age differences and a strong sexual dimorphism in the expression of UV-blue spots. Adult males had exaggerated number, area, and UV chroma of UV-blue spots while adult females and juveniles had only a few faint blue spots (see also López et al. 2004; Pérez i de Lanuza et al. 2014), indicating very limited trait expression in these groups. In adult males, we found a significant correlation between body size and both total spot area and largest left/right spot area, but considered that total spot area is likely to be more biologically relevant because it spans a large part of the length of the lizard, while largest spots do not. Our results therefore indicate that longer, possibly older, adult males have larger and more interspaced UVblue spots, possibly making them more conspicuous against their natural visual background. This 
453 result is noteworthy, as previous studies have not measured the coloration and morphological

454 properties of all spots of a single lizard (Pérez i de Lanuza et al. 2013; Martin et al. 2015b).

455 Different interpretations can be drawn to explain this relationship. First, UV-blue spot area may

456 be an honest signal of male quality and correlate with quality indicators not measured in this

457 study such as bite force, which has been shown to be related to male quality in lizards, especially

458 lacertids (Huyghe et al. 2005; Salvador et al. 2007; Henningsen and Irschick 2012; Pérez i de

459 Lanuza et al. 2014). Second, UV-blue spot area may be directly related to body size either

460 through an inherent relationship, in which case they would act as indices, or as amplifiers of

461 body size, to facilitate receivers' assessment of body size. Baeckens et al. (2018), for example,

462 argue that displaying sexual signals that are redundant with body size may be useful in the first

463 stages of a confrontation, when cryptic lizards must assess one another's quality at a certain

464 distance. Third, ontogenetic processes could also explain this relationship, which could be tested

465 in longitudinal studies following the same males as they age. For example, Bonnaffé et al. (2018)

466 showed that, in male common lizards Zootoca vivipara, UV chroma increased with age, likely

467 due to ontogenetic processes.

468 As argued above, recent evidence suggests that UV-blue spots are a signal of male

469 quality. The eventual strategic costs associated with these signals remain unknown. Thus, we

470 subsequently tested the prediction that total spot area may act as a conventional signal of male

471 quality (the honesty of which would be maintained by social costs) by conducting behavioral

472 assays between unfamiliar males of varying body size and manipulated spot area. During control

473 encounters, we found a positive relationship between body size and dominance score, and a

474 negative relationship between body size and wall scratching time. These results corroborated

475 previous findings showing that body size influences aggressive and submissive behaviors in male 
476 lizards (e.g., López and Martín 2001; Martin et al. 2015b). When we artificially created a

477 mismatch between body size and UV-blue spot area, we found that UV-blue spot area was not a

478 significant explanatory factor of dominance. If, as we aimed to test here, the UV-blue spots

479 functioned as conventional signals, the honesty of which is guaranteed by receiver-dependent

480 costs, we expected deceptive males to pay a socially induced cost for being dishonest (Maynard

481 Smith and Harper 2003; Ligon and McGraw 2016). Focal males were thus expected to invest

482 more in combat behaviors and escalation (both aggression and submission) when faced with a

483 deceptive male rather than a control male, with larger males eventually dominating smaller ones.

484 We, however, found that when facing deceptive opponents, the submission score of focal males

485 significantly increased while their dominance score tended to decrease. These results do not

486 support the prediction of a "conventional signal" hypothesis, in which deceptive males (i.e.

487 bluffers and Trojans) pay a social cost for being dishonest (Maynard Smith and Harper 2003;

488 Ligon and McGraw 2016), and suggest that other types of strategic costs must maintain signal

489 honesty (e.g., handicaps).

In addition, if the UV-blue spots act as an amplifier of body size, we would have

491 expected mismatching body size and spot area combinations to lead to combat escalation,

492 because visual assessment of opponents would fail to clearly establish dominance (Hasson 1989;

493 Maynard Smith and Harper 2003; Martin et al. 2015b). Unfortunately, in our behavioral assays,

494 it was generally not possible to establish a clear "winner" or "loser" over the course of the

495 competitive encounter, and thus we were not able to quantify combat escalation time. Yet, our

496 results showed that the artificial mismatch between UV-blue spot area and body size did

497 influence the competitive behavior of focal males. On one hand, focal males were more

498 submissive against bluffers than against controls, which could be expected if spot area serves as 
an amplifier of body size. On the other hand, focal males were also more submissive when faced with Trojans, which contradicts the predictions of the amplifier hypothesis.

One explanation for the weak effect of the combination of body size and spot manipulation treatments on encounters, apart from the submissive behavior of focal males, is that body size contrasts between males were small relative to the wall lizard body size range and, thus, that absolute body size was a better predictor of male behavior than size contrasts. In addition, the correlation between total spot area and body size was not strong (albeit significant, see Fig. 2), possibly suggesting that manipulation of total spot area might not have been perceived as a change in apparent body size. Experiments with a stronger size contrast and modifying the information content of the UV-blue spots in multiple ways (e.g., masking the first and last spots to reduce total length of the lateral rows) could shed light on this possibility. Another explanation is that color traits, such as UV-blue spots, may be more relevant to mutual assessment in outdoor conditions when direct assessment of body size is more difficult, such as signaling over long distances or in the presence of vision-impairing factors (e.g., poor lighting, presence of objects or other organisms, Henningsen and Irschick 2012). Wall lizards typically defend territories using behavioral displays performed at maximal distances of several meters in outdoor conditions (Edsman 1990), and physical pairwise interactions are often aggressive at our study site (J-FLG personal observation). Thus, in the future, the effects of spot manipulation on territory defense and male-male interactions should be tested outdoors. Then, although we did account for and found no relationship between belly morph and behavior in this study, Abalos et al. (2016) found consistent physiological and morphological differences in morph types that could, in turn, be related to morph-specific behavioral syndromes. It would be worth investigating whether morphs are associated with certain personality types that could influence 
522 competitive encounters. Finally, as was the case in studies involving blue tits (Johnsen et al.

523 2005; Rémy et al. 2010), the UV enhancing marker increased reflectance in the UV as well as

524 the 450-700 wavelength range (although the increase was less in the latter, see Fig. S3). The

525 increase in reflectance outside the UV could have affected opponent response to the manipulated 526 males and it would be ideal to find a UV enhancing product that increased reflectance only in the 527 UV-blue range of the spectrum.

Despite the lack of a strong effect, we did find that spot manipulation of the rival resulted

529 in increased submission and slightly decreased dominance in focal males irrespective of

530 opponent size. We suggest that this result could be explained if rivals enter into aggressive

531 encounters only if they believe they have a chance of winning based on a comparison of their

532 own and their opponents' color signals (Rohwer 1975; Rémy et al. 2010; Vedder et al. 2010). If

533 we assume that body size is a physical trait easily detected at short distances, large and small

534 focal males initially evaluating a manipulated opponent would likely behave as they normally

535 would against a small or big opponent. In manipulated individuals, focal males facing large

536 opponents would likely back down immediately and no change in their behavior would result

537 due to the manipulation. In focal males facing small opponents, the focal male may initially have

538 been aggressive. Upon approaching their opponent and detecting their enlarged spot area,

539 however, the focal male may back down or exhibit greater submission behaviors due to the

540 mismatch between body size and the signal, resulting in a decrease in overall dominance and

541 increase in overall submission. Another factor that could have reduced aggression is inadvertent

542 modification of black spots next to UV-blue spots. Black spots, sometimes adjacent to UV-blue

543 spots (see Fig. S2), have not been extensively investigated but have been found in one study

544 (Abalos et al. 2016) to be a predictor of fighting ability, with winners showing greater aggression 
545 in encounters with opponents of similar black spot area. It is possible that UV-blue spot

546 manipulations reduced black spot area, resulting in encounters between lizards with more

547 dissimilar black spot area and thus lower aggression. Altogether, however, these results suggest

548 that the relationship between UV-blue spots and male dominance is ambiguous in $P$. muralis,

549 similar to findings of Martin et al. (2015b) about spot UV reflectance. Spot properties are

550 involved in mutual assessment during male-male competition but do not influence behavioral

551 dominance as we would expect from a conventional signal or an amplifier of body size.

552 COMPLIANCE WITH ETHICAL STANDARDS

$553 \quad$ Funding

554 This research was supported by the Centre National de la Recherche Scientifique (CNRS).

555 Conflicts of Interest

556 We, the authors, declare no conflicts of interest.

557 Ethical Approval

558 Authorization No. Ce5/2011/044 allowed us to capture and manipulate wild animals for this

559 study. Ethical approval from an ethics committee was not necessary. All applicable international,

560 national, and/or institutional guidelines for the care and use of animals were followed. All

561 procedures performed in studies involving animals were in accordance with the ethical standards

562 of the institution at which the studies were conducted.

563 REFERENCES

564 Abalos J, Pérez i de Lanuza G, Carazo P, Font E (2016) The role of male coloration in the outcome of 565 staged contests in the European common wall lizard (Podarcis muralis). Behaviour 153:607-631

566 Andersson MB (1994) Sexual selection. Princeton University Press, Princeton

567 Andrade P, Pinho C, Pérez i de Lanuza G et al (2019) Regulatory changes in pterin and carotenoid genes 568 underlie balanced color polymorphisms in the wall lizard. P Natl Acad Sci USA 116:5633-5642 
Aronsson M, Gamberale-Stille G (2009) Importance of internal pattern contrast and contrast against the background in aposematic signals. Behav Ecol 20:1356-1362

Badiane A, Pérez i de Lanuza G, García-Custodio MC, Carazo P, Font E (2017) Colour patch size and measurement error using reflectance spectrophotometry. Methods Ecol Evol 8:1585-1593

Baeckens S, Driessens T, Huyghe K, Vanhooydonck B, Van Damme R (2018) Intraspecific variation in the information content of an ornament: why relative dewlap size signals bite force in some, but not all island populations of Anolis sagrei. Integr Comp Biol 58:25-37

Bajer K, Molnár O, Török J, Herczeg G (2011) Ultraviolet nuptial colour determines fight success in male European green lizards (Lacerta viridis). Biol Lett 7:866-868

Bajer K, Molnár O, Török J, Herczeg G (2012) Temperature, but not available energy, affects the expression of a sexually selected ultraviolet (UV) colour trait in male European green lizards. PLoS ONE 7:e34359

Bennett A, Cuthill I, Norris K (1994) Sexual selection and the mismeasure of color. Am Nat 144:848-860

Blumstein DT, Daniel JC (2007) Quantifying behavior the JWatcher way. Sinauer Associates, Sunderland

Bogaardt L, Johnstone RA (2016) Amplifiers and the origin of animal signals. Proc R Soc B $283: 20160324$

Bonnaffé W, Martin M, Mugabo M, Meylan S, Le Galliard JF (2018) Ontogenetic trajectories of body coloration reveal its function as a multicomponent nonsenescent signal. Ecol Evol 8:12299-12307

Bradbury J, Vehrencamp S (2011) Principles of animal communication. 2nd edn. Sinauer, Sunderland, MA

Cabido C, Galán P, López P, Martín J (2009) Conspicuousness-dependent antipredatory behavior may counteract coloration differences in Iberian rock lizards. Behav Ecol 20:362-370

Candolin U (2000) Male-male competition ensures honest signaling of male parental ability in the threespined stickleback (Gasterosteus aculeatus). Behav Ecol Sociobiol 49:57-61

Candolin U (2003) The use of multiple cues in mate choice. Biol Rev 78:575-595 
594 Carleton KL, Hárosi FI, Kocher TD (2000) Visual pigments of African cichlid fishes: evidence for ultraviolet vision from microspectrophotometry and DNA sequences. Vision Res 40:879-890

596

Castellano S, Cermelli P (2010) Attractive amplifiers in sexual selection: where efficacy meets honesty. Evol Ecol 24:1187-1197

Dawkins MS, Guilford T (1991) The corruption of honest signalling. Anim Behav 41:865-873

Doucet SM, Montgomerie R (2003) Multiple sexual ornaments in satin bowerbirds: ultraviolet plumage and bowers signal different aspects of male quality. Behav Ecol 14:503-509

Edsman L (1990) Territoriality and competition in wall lizards. Dissertation. University of Stockholm, Sweden

Etman EJ, Lelieveld HM, ten Cate C (2001) Male bill colour and competition in zebra finches. Behav Processes 55:119-124

Fitzpatrick S (1998) Colour schemes for birds: structural coloration and signals of quality in feathers. Ann Zool Fenn 35:67-77

Fleishman L (2000) Signal function, signal efficiency and the evolution of anoline lizard dewlap color. In: Epsmark Y, Amundsen TGR (eds) Animal signals: signalling and signal design in animal communication. Tapir Academic, Trondheim, pp 209-236

Fleishman LJ, Loew ER, Leal M (1993) Ultraviolet vision in lizards. Nature 365:397

Galeotti P, Pellitteri-Rosa D, Sacchi R, Gentilli A, Pupin F, Rubolini D, Fasola M (2010) Sex-, morphand size-specific susceptibility to stress measured by haematological variables in captive common wall lizard Podarcis muralis. Comp Biochem Phys A 157:354-363

Goldsmith TH (1990) Optimization, constraint, and history in the evolution of eyes. Q Rev Biol 65:281322

Gomez D (2006) AVICOL, a program to analyse spectrometric data. Available from the author upon request at dodogomez@yahoofr

Grether GF, Kolluru GR, Nersissian K (2004) Individual colour patches as multicomponent signals. Biol Rev 79:583-610 
621 Harper D (2006) Maynard Smith: amplifying the reasons for signal reliability. J Theor Biol 239:203-209

622 Hasson O (1989) Amplifiers and the handicap principle in sexual selection: a different emphasis. Proc R

$623 \quad$ Soc Lond B 235:383-406

624 Hasson O (1990) The role of amplifiers in sexual selection: an integration of the amplifying and the

$625 \quad$ Fisherian mechanisms. Evol Ecol 4:277-289

626 Hasson O (1991) Sexual displays as amplifiers: practical examples with an emphasis on feather

627 decorations. Behav Ecol 2:189-197

628 Hasson O (1997) Towards a general theory of biological signaling. J Theor Biol 185:139-156

629 Hebets EA (2004) Attention-altering signal interactions in the multimodal courtship display of the wolf 630 spider Schizocosa uetzi. Behav Ecol 16:75-82

631

632

633

634

635

636

637

638

639

640

641

642

643

644

Hebets EA, Papaj DR (2005) Complex signal function: developing a framework of testable hypotheses. Behav Ecol Sociobiol 57:197-214

Henningsen JP, Irschick DJ (2012) An experimental test of the effect of signal size and performance capacity on dominance in the green anole lizard. Funct Ecol 26:3-10

Huyghe K, Vanhooydonck B, Scheers H, Molina-Borja M, Van Damme R (2005) Morphology, performance and fighting capacity in male lizards, Gallotia galloti. Funct Ecol 19:800-807

Johnsen A, Delhey K, Schlicht E, Peters A, Kempenaers B (2005) Male sexual attractiveness and parental effort in blue tits: a test of the differential allocation hypothesis. Anim Behav 70:877-888

Johnstone RA (1998) Game theory and communication. In: Dugatkin LA, Reeve HK (eds) Game theory and animal behavior. Oxford University Press, Oxford, pp 94-117

Keyser AJ, Hill GE (2000) Structurally based plumage coloration is an honest signal of quality in male blue grosbeaks. Behav Ecol 11:202-209

Kokko H, López-Sepulcre A, Morrell LJ (2006) From hawks and doves to self-consistent games of territorial behavior. Am Nat 167:901-912 
645

646

647

648

649

650

651

652

653

654

655

656

657

658

659

660

661

662

663

664

665

666

667

Kurvers RH, Delhey K, Roberts ML, Peters A (2010) No consistent female preference for higher crown UV reflectance in blue tits Cyanistes caeruleus: a mate choice experiment. Ibis 152:393-396

Lappin AK, Brandt Y, Husak JF, Macedonia JM, Kemp DJ (2006) Gaping displays reveal and amplify a mechanically based index of weapon performance. Am Nat 168:100-113

LeBas NR, Marshall NJ (2000) The role of colour in signalling and male choice in the agamid lizard Ctenophorus ornatus. Proc R Soc Lond B 267:445-452

Ligon RA, McGraw KJ (2016) Social costs enforce honesty of a dynamic signal of motivation. Proc R Soc B 283:20161873

López P, Martín J (2001) Fighting rules and rival recognition reduce costs of aggression in male lizards, Podarcis hispanica. Behav Ecol Sociobiol 49:111-116

López P, Martín J, Cuadrado M (2004) The role of lateral blue spots in intrasexual relationships between male Iberian rock - lizards, Lacerta monticola. Ethology 110:543-561

López P, Muñoz A, Martín J (2002) Symmetry, male dominance and female mate preferences in the Iberian rock lizard, Lacerta monticola. Behav Ecol Sociobiol 52:342-347

Marshall KL, Stevens M (2014) Wall lizards display conspicuous signals to conspecifics and reduce detection by avian predators. Behav Ecol 25:1325-1337

Martin M, Le Galliard J-F, Meylan S, Loew ER (2015a) The importance of ultraviolet and near-infrared sensitivity for visual discrimination in two species of lacertid lizards. J Exp Biol 218:458-465

Martin M, Meylan S, Haussy C, Decencière B, Perret S, Le Galliard J-F (2016) UV color determines the issue of conflicts but does not covary with individual quality in a lizard. Behav Ecol 27:262-270

Martin M, Meylan S, Perret S, Le Galliard J-F (2015b) UV coloration influences spatial dominance but not agonistic behaviors in male wall lizards. Behav Ecol Sociobiol 69:1483-1491

Maynard Smith J, Harper D (2003) Animal signals. Oxford University Press, Oxford 
McGraw KJ, Mackillop EA, Dale J, Hauber ME (2002) Different colors reveal different information: how nutritional stress affects the expression of melanin-and structurally based ornamental plumage. $\mathrm{J}$ Exp Biol 205:3747-3755

Mugabo M, Perret S, Legendre S, Galliard JF (2013) Density - dependent life history and the dynamics of small populations. J Anim Ecol 82:1227-1239

Ord T, Klomp D, Garcia-Porta J, Hagman M (2015) Repeated evolution of exaggerated dewlaps and other throat morphology in lizards. J Evol Biol 28:1948-1964

Pérez i de Lanuza G, Carazo P, Font E (2014) Colours of quality: structural (but not pigment) coloration informs about male quality in a polychromatic lizard. Anim Behav 90:73-81

Pérez i de Lanuza G, Font E (2014) Ultraviolet vision in lacertid lizards: evidence from retinal structure, eye transmittance, SWS1 visual pigment genes and behaviour. J Exp Biol 217:2899-2909

Pérez i de Lanuza G, Font E (2015) Differences in conspicuousness between alternative color morphs in a polychromatic lizard. Behav Ecol 26:1432-1446

Pérez i de Lanuza G, Font E, Monterde J (2013) Using visual modelling to study the evolution of lizard coloration: sexual selection drives the evolution of sexual dichromatism in lacertids. J Evol Biol 26:1826-1835

Promislow DE, Montgomerie R, Martin TE (1992) Mortality costs of sexual dimorphism in birds. Proc R Soc Lond B 250:143-150

Pryke S, Griffith S (2007) The relative role of male vs. female mate choice in maintaining assortative pairing among discrete colour morphs. J Evol Biol 20:1512-1521

Pryke SR, Griffith SC (2006) Red dominates black: agonistic signalling among head morphs in the colour polymorphic Gouldian finch. Proc R Soc Lond B 273:949-957

R Core Team (2014) R: A language and environment for statistical computing. R Foundation for Statistical Computing, Vienna, Austria. http://www.R-project.org. 
692

Rémy A, Grégoire A, Perret P, Doutrelant C (2010) Mediating male-male interactions: the role of the UV blue crest coloration in blue tits. Behav Ecol Sociobiol 64:1839-1847

Rick IP, Bakker TCM (2008) Males do not see only red: UV wavelengths and male territorial aggression in the three-spined stickleback (Gasterosteus aculeatus). Naturwissenschaften 95:631-638

Roberts ML, Ras E, Peters A (2009) Testosterone increases UV reflectance of sexually selected crown plumage in male blue tits. Behav Ecol 20:535-541

Rohwer S (1975) The social significance of avian winter plumage variability. Evolution 29:593-610

Rowe C (1999) Receiver psychology and the evolution of multicomponent signals. Anim Behav 58:921931

Sacchi R, Pupin F, Gentilli A, Rubolini D, Scali S, Fasola M, Galeotti P (2009) Male-male combats in a polymorphic lizard: residency and size, but not color, affect fighting rules and contest outcome. Aggressive Behav 35:274-283

Salvador A, Díaz JA, Veiga JP, Bloor P, Brown RP (2007) Correlates of reproductive success in male lizards of the alpine species Iberolacerta cyreni. Behav Ecol 19:169-176

Schneider CA, Rasband WS, Eliceiri KW (2012) NIH Image to ImageJ: 25 years of image analysis. Nat Methods 9:671

Searcy WA, Nowicki S (2005) The evolution of animal communication: reliability and deception in signaling systems. Princeton University Press, Princeton

Seehausen O, Schluter D (2004) Male-male competition and nuptial-colour displacement as a diversifying force in Lake Victoria cichlid fishes. Proc R Soc Lond B 271:1345-1353

Senar JC (1999) Plumage coloration as a signal of social status. In: Adams NJ, Slotow RH (eds) Proceedings of the 22nd International Ornithological Congress, BirdLife South Africa, Johannesburg, pp 1669-1686.

Siddiqi A, Cronin TW, Loew ER, Vorobyev M, Summers K (2004) Interspecific and intraspecific views of color signals in the strawberry poison frog Dendrobates pumilio. J Exp Biol 207:2471-2485 
Siebeck UE (2004) Communication in coral reef fish: the role of ultraviolet colour patterns in damselfish territorial behaviour. Anim Behav 68:273-282

Siebeck UE, Parker AN, Sprenger D, Mäthger LM, Wallis G (2010) A species of reef fish that uses ultraviolet patterns for covert face recognition. Curr Biol 20:407-410

Siefferman L, Hill GE (2005) UV-blue structural coloration and competition for nestboxes in male eastern bluebirds. Anim Behav 69:67-72

Siitari H, Alatalo RV, Halme P, Buchanan KL, Kilpimaa J (2007) Color signals in the black grouse (Tetrao tetrix): signal properties and their condition dependency. Am Nat 169:S81-S92

Smith EJ, Partridge JC, Parsons KN, White EM, Cuthill IC, Bennett AT, Church SC (2002) Ultraviolet vision and mate choice in the guppy (Poecilia reticulata). Behav Ecol 13:11-19

Speybroeck J, Beukema W, Bok B, van der Voort J (2016) Field guide to the amphibians and reptiles of Britain and Europe. Bloomsbury Publishing, London

Stapley J, Whiting MJ (2006) Ultraviolet signals fighting ability in a lizard. Biol Lett 2:169-172

Stoddard MC, Prum RO (2008) Evolution of avian plumage color in a tetrahedral color space: a phylogenetic analysis of new world buntings. Am Nat 171:755-776

Taylor P, Hasson O, Clark D (2000) Body postures and patterns as amplifiers of physical condition. Proc R Soc Lond B 267:917-922

Vacher J-P, Geniez M (2010) Les reptiles de France, Belgique, Luxembourg et Suisse. Biotope, Mèze Vanhooydonck B, Herrel A, Van Damme R, Irschick D (2005) Does dewlap size predict male bite performance in Jamaican Anolis lizards? Funct Ecol 19:38-42

Vedder O, Schut E, Magrath MJ, Komdeur J (2010) Ultraviolet crown colouration affects contest outcomes among male blue tits, but only in the absence of prior encounters. Funct Ecol 24:417425

Vehrencamp SL (2000) Handicap, index, and conventional signal elements of bird song. In: Espmark Y, Amundsen T, Rossenqvist G (eds) Animal signals: Signalling and signal design in animal communication. Tapir Academic Press, Trondheim, pp 277-300 
Vervust B, Van Damme R (2009) Marking lizards by heat branding. Herpetol Rev 40:173

Vorobyev M, Osorio D (1998) Receptor noise as a determinant of colour thresholds. Proc R Soc Lond B $265: 351-358$

Whiting MJ, Stuart-Fox DM, O'Connor D, Firth D, Bennett NC, Blomberg SP (2006) Ultraviolet signals ultra-aggression in a lizard. Anim Behav 72:353-363

Zahavi A (1975) Mate selection—a selection for a handicap. J Theor Biol 53:205-214

\section{FIGURE AND TABLE CAPTIONS}

Table 1 List and description of 1) behaviors displayed by $P$. muralis during male encounters, 2) scores used in analyses of behavior data

Table 2 Mean \pm SE chromatic contrast of flank and spot spectra in jnds (just noticeable differences). Flank vs. habitat and spot vs. habitat analyses compared individual flank and spot spectra, respectively, to each of 8 habitat object spectra. Spot vs. flank analyses compared individual spot spectra to a mean flank spectrum. $\mathrm{N}_{1}$ and $\mathrm{N}_{2}$ represent the number of spectra of the $1^{\text {st }}$ and $2^{\text {nd }}$ comparison elements, respectively

Table 3 Age $(\mathrm{A}=$ adults, $\mathrm{J}=$ juveniles $)$ and sex $(\mathrm{M}=$ males, $\mathrm{F}=$ females $)$ differences in spot morphology qualities. Except total number of spots, all factors are in $\mathrm{cm}^{2} . \beta$ were calculated on the transformed scale

Table 4 Effects of belly color morph $(\mathrm{O}=$ orange, $\mathrm{W}=$ white $)$ and SVL on spot characteristics in adult males. Except total number of spots and mean spot chroma, all factors are in $\mathrm{cm}^{2} . \beta$ were calculated on the transformed scale

Fig. 1 Mean reflectance spectra and $95 \%$ confidence interval curves of UV-blue spots for males and females. The male mean spectrum distinctly peaks in reflectance in the UV region $(\lambda \max =$ 360-365 nm) while the female mean spectrum has a weak UV reflectance and a flat reflectance 
767 curve in the visible range. Curves were calculated from raw data without smoothing and

768 confidence intervals assume a normal distribution

769 Fig. 2 Size scaling of the number and area of UV-blue spots. a) Total number of spots as a

770 function of SVL (snout-vent length) for adult male and adult female data with their respective

771 best-fit linear trend lines. The relationship between SVL and number of spots was not significant

772 for male or female data. b) Total spot area as a function of SVL. The relationship between SVL

773 and total spot area is significant for males and not for females (see text)

774 Fig. 3 Dominance score in the control experiments as a function of SVL (snout-vent length) with

775 the corresponding best-fit linear trend line. The relationship between SVL and dominance score

776 is significant (see text). The zero line represents situations in which males performed equal

777 numbers of aggressive and submissive behaviors 
Click here to access/download Marked manuscript BEAS_final changes_v2.docx 


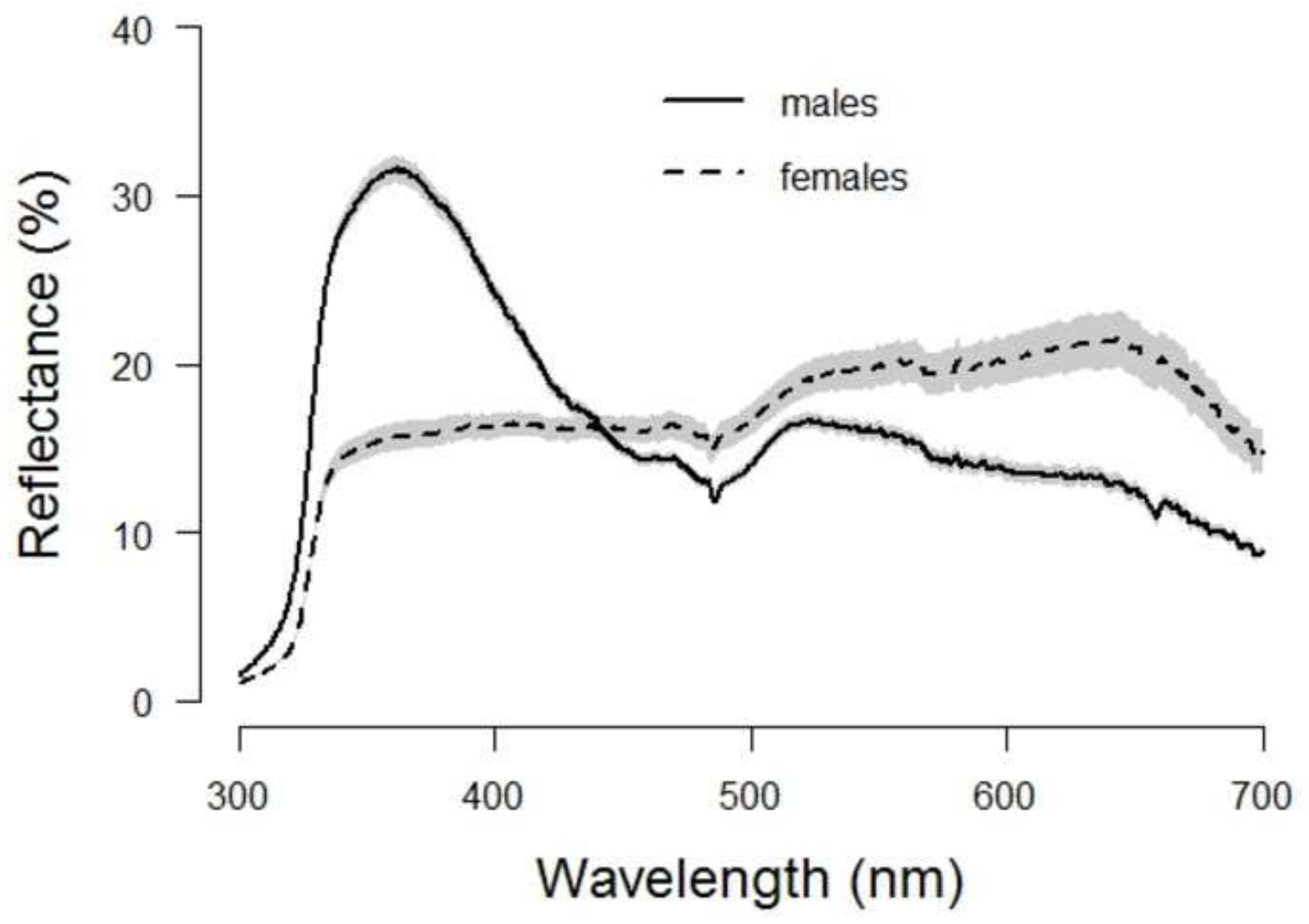



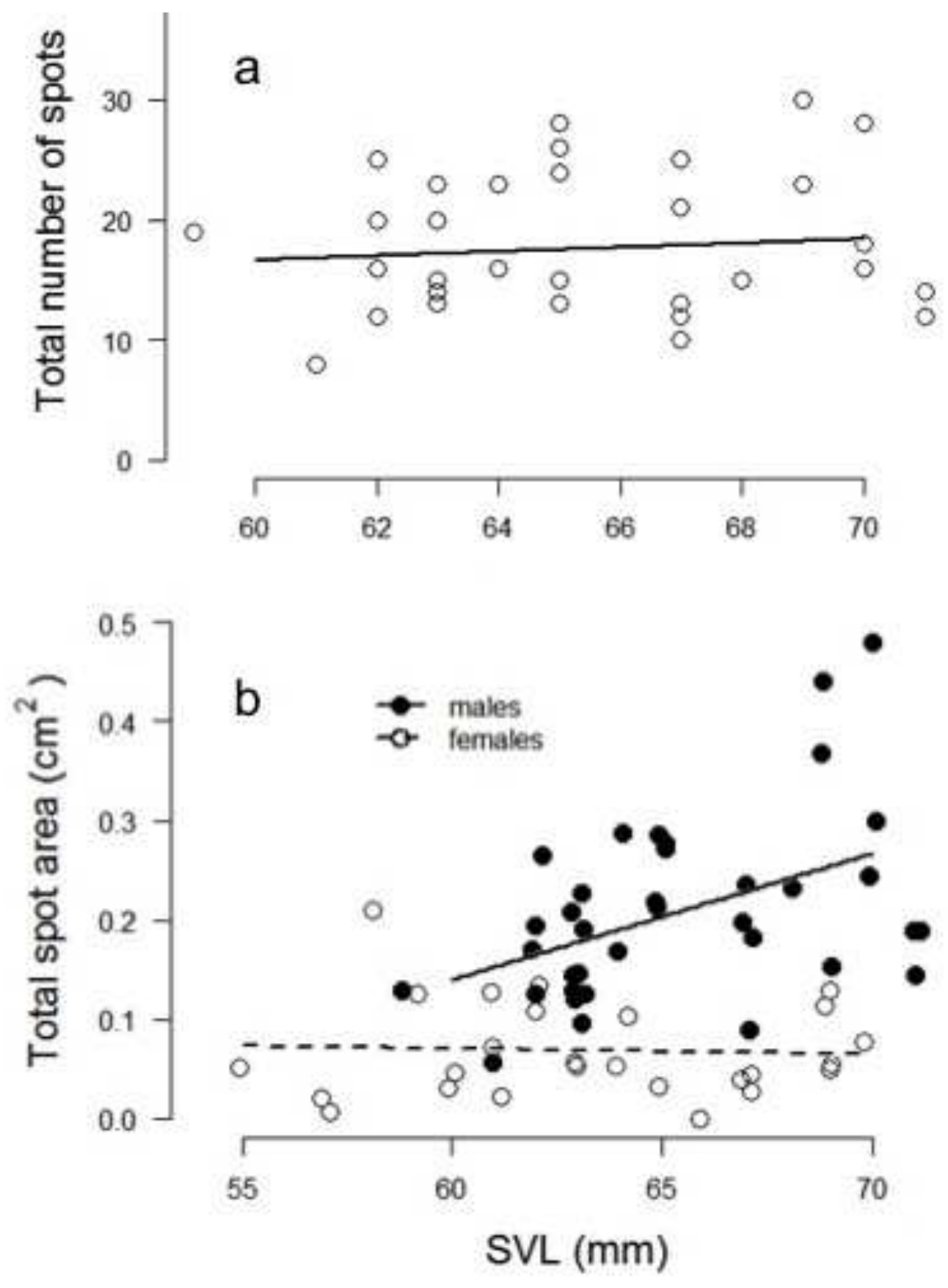

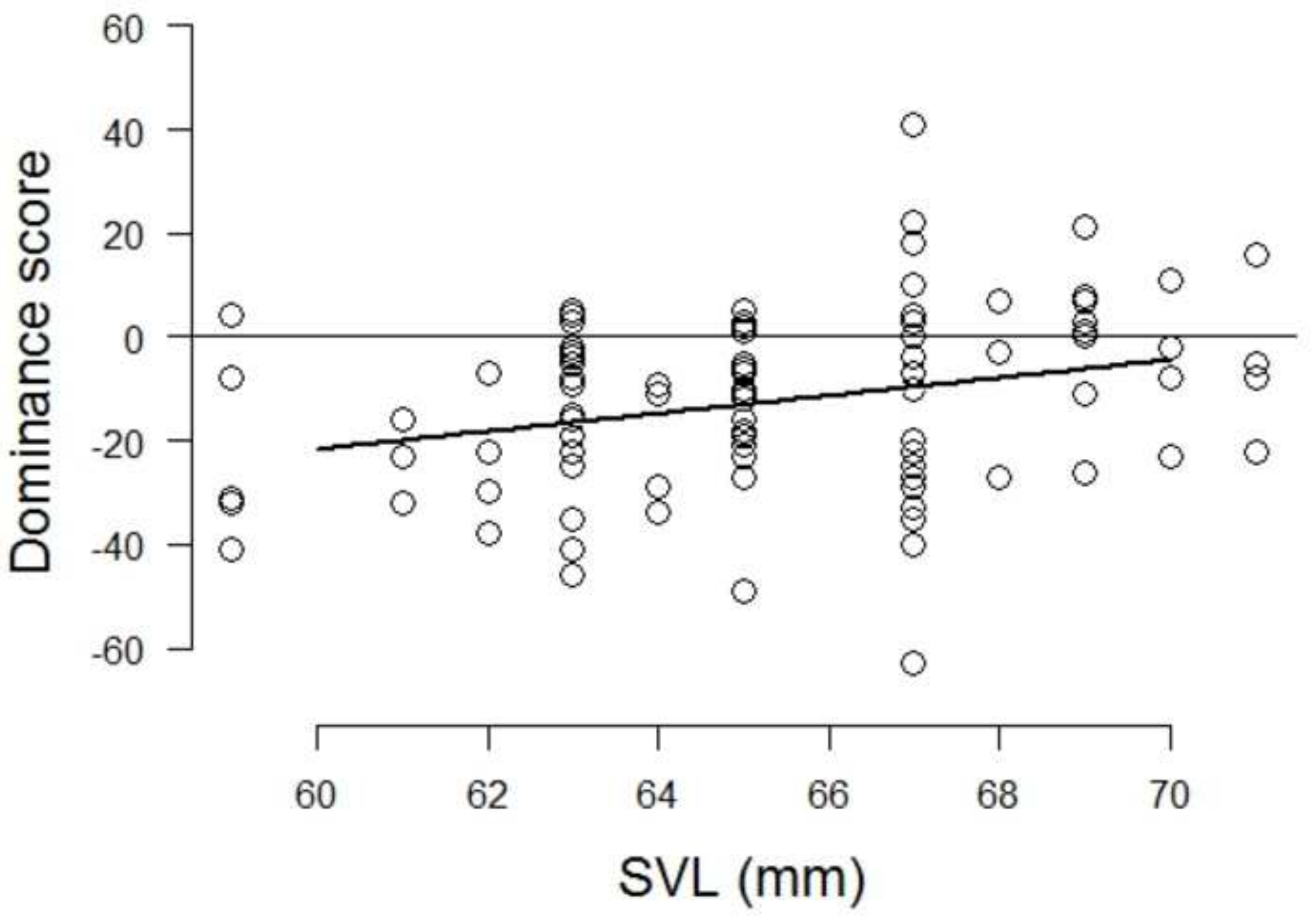


\begin{tabular}{c|l|l}
\hline \multicolumn{2}{c|}{ Behaviors/Scores } & \multicolumn{1}{c}{ Description } \\
\hline \multirow{2}{*}{} & Aggression & Rapid approach towards the opponent OR touch the opponent without bite \\
\cline { 2 - 3 } & Approach & Slow cautious approach to the opponent \\
\cline { 2 - 3 } & Bite & Prehension of a body part of the opponent with teeth \\
\cline { 2 - 3 } & \multirow{2}{*}{ Demonstration } & $\begin{array}{l}\text { Stationary position with alternately, jerked up and down movements of the } \\
\text { hind legs OR wide sustained opening of jaws OR exhibiting one flank by } \\
\text { postural adjustement towards the opponent }\end{array}$ \\
\cline { 2 - 3 } & Escape & Bypass OR rapid movement away from the opponent \\
\cline { 2 - 3 } & Wall & $\begin{array}{l}\text { Scratching the wall of the terrarium, a sign of moderate stress or avoidance } \\
\text { behavior }\end{array}$ \\
\hline \multirow{3}{*}{} & Scratching & $\begin{array}{l}\text { The body is flattened onto the substrate and oriented at right angles to a } \\
\text { heat source }\end{array}$ \\
\cline { 2 - 3 } & Basking & Movement from one place to another \\
\cline { 2 - 3 } & Immobility & No movement while on feet. \\
\cline { 2 - 3 } & "Aggression" & Aggressions + approaches + demonstrations \\
\cline { 2 - 3 } & "Submission" & Escapes + tail wag events + wall scratching events \\
\cline { 2 - 3 } & "Dominance" & Aggression score - submission score \\
\hline
\end{tabular}




\begin{tabular}{lccccccccc}
\hline & \multicolumn{2}{c}{ Flank vs. Habitat } & \multicolumn{3}{c}{ Spots vs. Habitat } & \multicolumn{2}{c}{ Spots vs. Mean flank } \\
\cline { 2 - 9 } & $\mathrm{N}_{1}$ & $\mathrm{~N}_{2}$ & mean $\pm \mathrm{SE}$ & $\mathrm{N}_{1}$ & $\mathrm{~N}_{2}$ & mean $\pm \mathrm{SE}$ & $\mathrm{N}_{1}$ & $\mathrm{~N}_{2}$ & mean \pm SE \\
\hline Adult Males & 67 & 8 & $6.50 \pm 0.18$ & 454 & 8 & $26.25 \pm 0.14$ & 454 & 1 & $25.72 \pm 0.32$ \\
& & & & & & & & & \\
\hline Adult Females & 25 & 8 & $6.45 \pm 0.30$ & 125 & 8 & $11.97 \pm 0.27$ & 125 & 1 & $11.02 \pm 0.68$ \\
\hline Juveniles & 13 & 8 & $7.97 \pm 0.52$ & 72 & 8 & $19.78 \pm 0.36$ & 72 & 1 & $19.14 \pm 0.90$ \\
\hline
\end{tabular}




\begin{tabular}{|c|c|c|c|c|c|c|}
\hline \multirow[b]{2}{*}{ Spot properties } & \multicolumn{3}{|c|}{$\operatorname{Sex}(d f=1,65)$} & \multicolumn{3}{|c|}{ Age $(d f=1,72)$} \\
\hline & $F$ & $p$ & $\beta$ (M vs. F) & $F$ & $p$ & $\beta$ (A vs. J) \\
\hline Total spot area & 46.46 & $<0.0001$ & $0.18 \pm 0.026$ & 12.49 & 0.00072 & $0.14 \pm 0.040$ \\
\hline Total number of spots & 5.28 & 0.025 & $3.40 \pm 1.48$ & 3.75 & 0.057 & $3.72 \pm 1.92$ \\
\hline Largest left flank spot area & 47.39 & $<0.0001$ & $0.0083 \pm 0.0012$ & 14.42 & 0.00030 & $0.0068 \pm 0.0018$ \\
\hline Largest right flank spot area & 49.34 & $<0.0001$ & $0.047 \pm 0.0066$ & 14.12 & 0.00035 & $0.040 \pm 0.011$ \\
\hline
\end{tabular}




\begin{tabular}{|c|c|c|c|c|c|c|}
\hline \multirow[b]{2}{*}{ Spot properties } & \multicolumn{3}{|c|}{ Color $(\mathrm{df}=1,33)$} & \multicolumn{3}{|c|}{ SVL $(d f=1,33)$} \\
\hline & $\mathrm{F}$ & $p$ & $\beta(\mathrm{O}$ vs. $\mathrm{W})$ & $\mathrm{t}$ & $p$ & $\beta$ \\
\hline Total spot area & 2.08 & 0.16 & $0.27 \pm 0.18$ & 2.27 & 0.030 & $0.057 \pm 0.025$ \\
\hline Total number of spots & 3.81 & 0.059 & $0.24 \pm 0.12$ & 0.48 & 0.63 & $0.0079 \pm 0.017$ \\
\hline Largest left flank spot area & 0.33 & 0.57 & $-0.0011 \pm 0.0019$ & 2.61 & 0.014 & $0.0006 \pm 0.0002$ \\
\hline Largest right flank spot area & 0.063 & 0.80 & $6.50 \times 10^{-4} \pm 2.59 \times 10^{-4}$ & 2.67 & 0.012 & $0.0009 \pm 0.0003$ \\
\hline Mean spot UV chroma & 7.49 & 0.010 & $0.062 \pm 0.023$ & 1.09 & 0.28 & $0.0034 \pm 0.0031$ \\
\hline
\end{tabular}


Click here to access/download Supplementary Material supplementary_clean.docx 


\section{SPRINGER NATURE Change of authorship request form}

\section{Please read the important information on page 4 before you begin}

This form should be used by authors to request any change in authorship. Please fully complete all sections. Use black ink and block capitals and provide each author's full name with the given name first followed by the family name.

Section 1 Please provide the current title of manuscript

Manuscript ID no. BEAS-D-18-00411R3

The relative importance of body size and UV coloration in influencing male-male competition in a Lacertid lizard

Section 2 Please provide the current authorship, in the order shown on your manuscript.

\begin{tabular}{|l|l|l|l|}
\hline & First name(s) & Family name & ORCID or SCOPUS id, if available \\
\hline $1^{\text {st }}$ author & Gabrielle & Names & \\
\hline $2^{\text {nd }}$ author & Mélissa & Martin & \\
\hline $3^{\text {rd }}$ author & Jean-François & Le Galliard & \\
\hline
\end{tabular}

Please use an additional sheet if there are more than 7 authors.

Section 3: Please provide a justification for change. Please use this section to explain your reasons for changing the authorship of your manuscript. Please refer to the journal policy pages for more information about authorship. Please explain why omitted authors were not originally included on the submitted manuscript.

Dr. Arnuad Badiane was not originally an author of the manuscript and has now been added as a co-author of the manuscript. Dr. Badiane was not originally on the submitted manuscript because Dr. Badiane had not initially been involved in the research or writing of the manuscript. However, Dr. Badiane made a major contribution to the last substantial revision of the manuscript. Thanks to Dr. Badiane's expertise in the signalling literature, we were able to substantially modify the introduction and discussion of the manuscript in order to focus more heavily on the conventional signal hypothesis and less on the amplifier hypothesis in response to the concerns of one of the reviewers. These changes would not have been possible without Dr. Badiane's assistance and thus decided that he merited co-authorship. 


\section{SPRINGER NATURE Change of authorship request form}

Section 4 Proposed new authorship. Please provide your new authorship list in the order you would like it to appear on the manuscript.

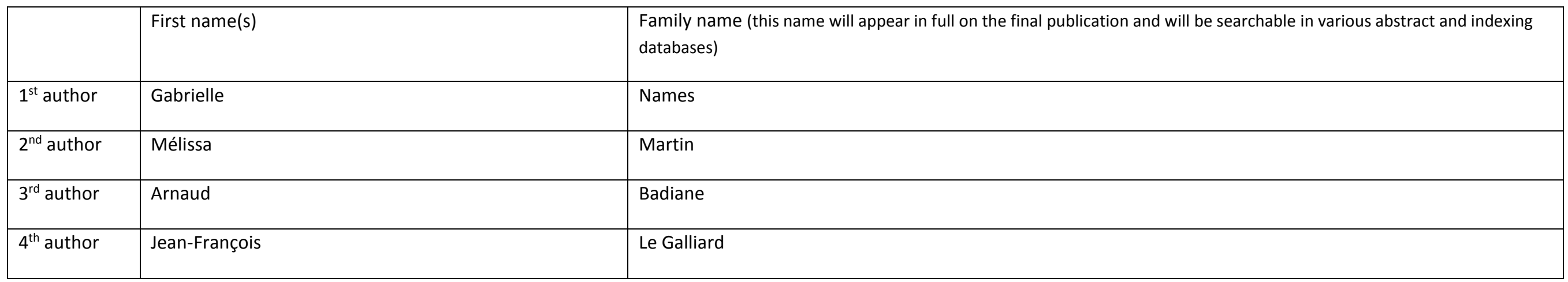

Please use an additional sheet if there are more than 7 authors.

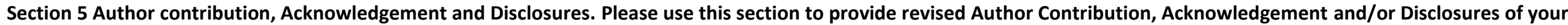

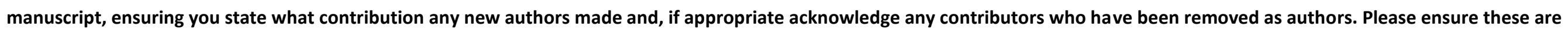
updated in your manuscript.

New Disclosures (potential conflicts of interest, funding, acknowledgements):

\section{Funding}

This research was supported by the Centre National de la Recherche Scientifique (CNRS).

\section{Conflicts of Interest}

We, the authors, declare no conflicts of interest.

\section{Acknowledgements}

We thank Cécile Vande Maele, Samuel Perret and Beatriz Decencière Ferrandière for their help in the laboratory.

\section{New Author Contributions statement:}

Dr. Badiane made a major contribution to the last substantial revision of the manuscript. Thanks to Dr. Badiane's expertise in the signalling literature, we were able to substantially 


\section{SPRINGER NATURE Change of authorship request form}

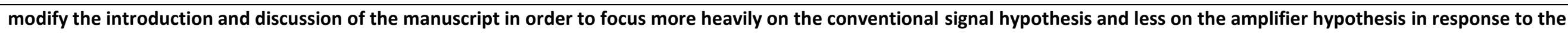
concerns of one of the reviewers. These changes would not have been possible without Dr. Badiane's assistance.

New Acknowledgement Section:

We thank Cécile Vande Maele, Samuel Perret and Beatriz Decencière Ferrandière for their help in the laboratory.

State 'Not applicable' if there are no new authors.

Section 6 Declaration of agreement. All authors, unchanged, new and removed must sign this declaration.

* please delete as appropriate. Delete all of the bold if you were on the original authorship list and are remaining as an author

\begin{tabular}{|c|c|c|c|c|c|c|}
\hline & First name & Family name & & Signature & Affiliated institute & Date \\
\hline $\begin{array}{l}1^{\text {st }} \\
\text { author }\end{array}$ & Gabrielle & Names & $\begin{array}{l}\text { I agree to the proposed new } \\
\text { authorship shown in section } 4 \text { /and } \\
\text { the addition/removal*of my name } \\
\text { to the authorship list. }\end{array}$ & Mabuiderianos & University of California Davis & 21 March 2019 \\
\hline $\begin{array}{l}2^{\text {nd }} \\
\text { author }\end{array}$ & Mélissa & Martin & $\begin{array}{l}\text { I agree to the proposed new } \\
\text { authorship shown in section } 4 \text { /and } \\
\text { the addition/removal*of my name } \\
\text { to the authorship list. }\end{array}$ & & & 25 March 2019 \\
\hline $\begin{array}{l}3^{\text {rd }} \\
\text { author }\end{array}$ & Arnaud & Badiane & $\begin{array}{l}\text { I agree to the proposed new } \\
\text { authorship shown in section } 4 \text { /and } \\
\text { the addition/removal*of my name } \\
\text { to the authorship list. }\end{array}$ & & $\begin{array}{l}\text { iEES Paris, UMR 7618, Sorbonne } \\
\text { Univiersité }\end{array}$ & 21 March 2019 \\
\hline
\end{tabular}




\section{SPRINGER NATURE Change of authorship request form}

\begin{tabular}{|c|c|c|c|c|c|}
\hline $\begin{array}{l}4^{\text {th }} \\
\text { authors }\end{array}$ & Jean-Francois & Le Galliard & $\begin{array}{l}\text { I agree to the proposed new } \\
\text { authorship shown in section } 4 \text { /and } \\
\text { the addition/removal* of my name } \\
\text { to the authorship list. }\end{array}$ & $\begin{array}{l}\text { iEES Paris, UMR 7618, Sorbonne } \\
\text { Univiersité }\end{array}$ & 25 March 2019 \\
\hline
\end{tabular}

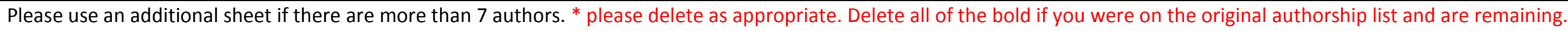

\section{Important information. Please read.}

- Please return this form, fully completed, to the editorial office. We will consider the information you have provided to decide whether to approve the proposed change in authorship. We may choose to contact your institution for more information or undertake a further investigation, if appropriate, before making a final decision.

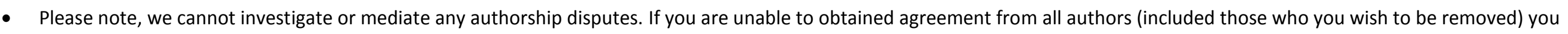
must refer the matter to your institution(s) for investigation. Please inform us if you need to do this.

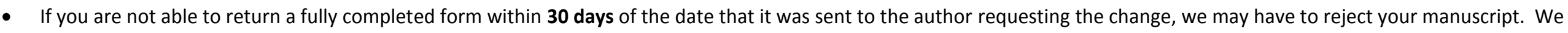
cannot publish manuscripts where authorship has not been agreed by all authors (including those who have been removed).

- Incomplete forms will be rejected. 